\title{
HOSPITALIDADE EM CAMPINGS E REFÚGIOS COMO ALTERNATIVAS ECONÔMICAS EM PEQUENAS PROPRIEDADES RURAIS SITUADAS EM ÁREAS PROTEGIDAS DE MATA ATLÂNTICA DA REGIÃO SERRANA CENTRAL DO ESTADO DO RIO DE JANEIRO, RJ.
}

\author{
Carlos Eduardo dos Santos Diniz ${ }^{1}$
}

\section{RESUMO}

A pesquisa compreende um diagnóstico preliminar sobre a oferta turística nos distritos de Guapiaçu, na Área de Proteção Ambiental (APA) da Bacia do Rio Macacu, Lumiar e Campo do Coelho, na APA Macaé de Cima e Parque Estadual dos Três Picos, nos municípios de Cachoeiras de Macacu e Nova Friburgo, respectivamente. Os objetivos foram caracterizar a oferta de meios de hospedagem e campings que empregam mão de obra familiar, facilitando o acesso e a permanência do turista próximo a atrativos naturais característicos da floresta atlântica e contribuindo para a consolidação de fluxos turísticos e a recuperação ambiental em áreas com uso do solo predominantemente agrícola da região serrana central fluminense. Foi adotada uma abordagem qualitativa-quantitativa através de entrevistas com perguntas abertas com prestadores de serviços turísticos, contribuindo para o conhecimento do desempenho e satisfação dos microempreendedores com estas atividades nestas localidades. Nas entrevistas ficou evidente que a Hospitalidade dos Campings e Refúgios é mais doméstica do que profissional, constituindo uma fonte de renda complementar que auxilia as despesas com a manutenção da residência e da pequena propriedade rural.

Palavras-chave: Oferta turística; Hospitalidade; Floresta Atlântica.

\begin{abstract}
The research comprises a preliminary diagnosis of the tourism offer in Guapiaçu district, on the Environmental Protection Area (APA) of the Macacu River Basin, Lumiar and Campo do Coelho, on the Environmental Protection Area of Macaé de Cima and Three Peaks State Park, in the municipalities of Cachoeiras de Macacu and Nova Friburgo, respectively. The objectives were to characterize the offer of lodging facilities and campgrounds that employ family labor, granting access for tourists to stay close to natural typical attractions of the Atlantic forest, contributing to the consolidation of tourism and environmental restoration in areas that have been predominantly used for agricultural land in the central mountainous region of the State of Rio de Janeiro. The qualitative and quantitative approach was adopted through interviews with open-ended questions with tourism service providers, contributing to understanding the performance and satisfaction of microentrepreneurs with these activities on these locations. In the interviews it became clear that the Hospitality in Campsites and Shelters is more domestic than commercial, providing a source of additional income that helps the cost of maintaining the house and small farm.
\end{abstract}

Keywords: Tourism offer; Hospitality; Atlantic forest.

${ }^{1}$ Biólogo, Instituto Estadual do Ambiente (INEA-RJ). E-mail: dossdiniz@ig.com.br 


\section{INTRODUÇÃO}

$\mathrm{O}$ ambiente de regiões montanhosas reune atributos que influenciam diretamente a história e o grau de ocupação humana, o desenho de cidades e áreas agrícolas, podendo trazer benefícios para iniciativas de microempreendedores em atividades econômicas alternativas à agropecuária em pequenas propriedades rurais. Em uma unidade territorial, relevo, hidrografia, clima, vegetação, fauna, juntos impõem possibilidades e limites para o Ecoturismo, selecionam o tipo e a frequência dos visitantes.

Com o aumento das opções de consumo por meio eletrônico na sociedade contemporânea, empresas de turismo e meios de hospedagem vem buscando um melhor posicionamento no mercado devido a uma maior concorrência entre cidades e regiões remotas pela oferta de destinos turísticos. Neste contexto, a permanência de prestadores de serviços turísticos satisfeitos com sua atividade depende dos vínculos entre as forças do atrativo, a qualidade da infraestrutura básica, os efeitos da concorrência, a procura pelos turistas e a satisfação do cliente proporcionada pela sua hospitalidade e acomodações. Estas seriam condições gerais para o retorno e atração de novos turistas.

Para que a segmentação do turismo seja efetiva, é necessário conhecer profundamente as características do destino: a oferta (atrativos, infraestrutura, serviços e produtos turísticos) e a demanda (as especificidades dos grupos de turistas que já o visitam ou que virão a visitá-lo). $\mathrm{Ou}$ seja, quem entende melhor os desejos da demanda e promove a qualificação ou aperfeiçoamento de seus destinos e roteiros com base nesse perfil, terá mais facilidade de inserção, posicionamento ou reposicionamento no mercado ${ }^{2}$.

A prestação de serviços pelo comércio e meios de hospedagem na zona rural se reveste de uma relevância maior do que a simples relação de consumo, uma vez que se constituem em espaços de diálogo, interação social e difusão de informações, incluindo a divulgação dos atrativos naturais e unidades de conservação locais, reforçando seu papel como equipamentos turísticos estratégicos para o uso público em áreas protegidas.

\section{Turismo e Hospitalidade em Pequenas Propriedades Rurais}

Como um componente essencial do turismo receptivo, a Hospitalidade é um conceito que abrange aspectos psicossociais, culturais, técnicos e econômicos, compreende o conjunto de bens e serviços a disposição do hóspede durante sua permanência no destino turístico mas envolve também o comportamento individual e coletivo no ato de "bem receber". A Hospitalidade pode ser definida como a "1. ação de hospedar ; hospedagem.2.qualidade de hospitaleiro.3.tratamento afável e acolhedor dispensado a alguém ${ }^{3}$.

\footnotetext{
${ }^{2}$ BRASIL. Ministério do Turismo, Segmentação do turismo e o mercado, 2010.

${ }^{3}$ Dicionário escolar da língua portuguesa/Academia Brasileira de Letras, $2^{\mathrm{a}}$ ed.São Paulo:Companhia Editora Nacional, 2008:674
} 
A hospitalidade não se restringe a simples oferta de abrigo e alimentação ao visitante, trata-se de um fenômeno sociocultural, político, profissional e espacial, em parte é "fruto da organização socioespacial do lugar", se refere ao "acolher". Para Cooper et al. (2001, apud Cruz, 2002), a hospitalidade profissional compreende como características:

- é a combinação complexa de benefícios e aspectos intangíveis e tangíveis;

- envolve a interação satisfatória entre serviço e prestador, consumidor e hóspede;

- oferece ao hóspede segurança, conforto psicológico e fisiológico, com alimentação, bebida e acomodação, e;

- pode ser lucrativa ou não;

A atração e satisfação das necessidades de visitantes, turistas e hóspedes são requisitos básicos para se desenvolver um produto turístico, seja um atrativo natural ou cultural, uma rota ou região turística. Não há como dissociar a satisfação promovida pela visita a um atrativo turístico, da hospitalidade que é percebida pelo turista, seja visitante ou hóspede. Segundo a conceituação tradicional, o turista é aquele que viaja com finalidade de recreação (IGNARRA,1999); quando uma pessoa viaja e permanece menos de $24 \mathrm{~h}$ em local diferente de onde tenha residência habitual, é conceituado como excursionista ou turista de um dia; quando não pernoita, se hospeda em residências secundárias ou casa de familiares, é conceituado como visitante; e, segundo conceituação da ONU, de 1954, o turista é qualquer pessoa que permaneça por um período mínimo de $24 \mathrm{~h}$ e máximo de seis meses, no transcorrer de um período de 12 meses com finalidade de turismo, recreio, esporte, saúde, motivos familiares, estudos, peregrinações religiosas ou negócios, mas sem propósito de imigração" (IGNARRA, op.cit.)

Com a tendência de aumento do fluxos de entrada de turistas no Brasil ${ }^{4}$ nos últimos anos, alguns autores vem tecendo críticas aos estudos recentes e a incidência das políticas públicas que dão ênfase ao turista e à viagem, uma preocupação excessiva com números, índices, valores financeiros, padronização de estruturas e procedimentos (PACHECO E IRVING, 2002). Mantendo este mesmo sentido crítico, o autor Luiz Otávio L. Camargo propõe a designação Hospitalidade, e não Hotelaria, que seria justificada por permitir a reelaboração de referenciais teóricos de pesquisa voltados para o hóspede, o residente. (CAMARGO, 2003).

Considerando a existência valiosa de pesquisas sobre a Hospitalidade, os trabalhos de D’Onofre (2010; 2014) vem contribuindo para o conhecimento das relações urbano-rural, ou "ruralidades" formadas em regiões turísticas de Nova Friburgo. Analisando as relações anfitrião-hóspede nos circuitos turísticos Teresópolis-Friburgo (CTTF) e Três Picos (CTTP), argumenta que a comercialização da hospitalidade no distrito friburguense de Campo do Coelho revela em si a hibridização do rural com o urbano, bem como do comercial com o doméstico, e que a base para a construção da hospitalidade comercial é a hospitalidade

\footnotetext{
${ }^{4}$ Considerando as vias de acesso marítimo e aéreo, desembarcaram no Estado do Rio de Janeiro em 2012-2013, respectivamente, 1.164 .187 e 1.207 .800 turistas. (fonte: DPF/Ministério do Turismo)
} 
doméstica: "a comercialização da hospitalidade rural, bem imaterial que envolve os serviços de alimentação, recepção, hospedagem e entretenimento, presta-se como um dos fatores principais para a criação de um mercado turístico. (D’ONOFRE,2014:13)

\section{OBJETIVOS}

A presente pesquisa tem como objetivo geral contribuir para o planejamento turístico através de um conhecimento mais detalhado sobre a oferta de prestadores de serviços como meios de hospedagem e acampamentos turísticos (campings) e, como objetivos específicos: 1) identificar a capacidade de alojamento de visitantes, período de atividade e pessoal ocupado em meios de hospedagem do tipo "refúgio de montanha" e campings; 2) avaliar as condições em que ocorreu a escolha do local, e como ocorreu a preparação desde a inauguração, as estratégias de comunicação, o desempenho e a satisfação dos microempreendedores com os resultados obtidos.

\section{MATERIAL E MÉTODOS}

A metodologia compreendeu uma abordagem quali-quantitativa, buscando o levantamento das iniciativas privadas de meios de hospedagem e campings apoiados por unidades domésticas que utilizam predominantemente mão de obra familiar e temporária.

Inicialmente, nos meses de fevereiro e março de 2015, foram realizadas buscas pela internet e consultas com informantes que trabalham em órgãos públicos municipais, havendo um primeiro contato por telefone com os responsáveis pelas atividades. Nos meses de abril e maio foi realizada uma pesquisa de campo baseada em observação participante e entrevistas estruturadas registradas em gravador de áudio nos respectivos Campings e Refúgios, quando os responsáveis foram questionados se sabiam da existência de outros prestadores deste tipo de serviço com as mesmas características nas localidades, como tinham adquirido e se preparado para instalar e desenvolver a atividades de hospedagem entre outros serviços de apoio.

Para a análise, os dados colhidos nas entrevistas foram transcritos integralmente, sendo agrupados em unidades temáticas conforme foram surgindo nas falas dos entrevistados buscando enfatizar características que permitam a definição de uma identidade do discurso em torno das práticas conservacionistas, da infraestrutura de apoio e de uma auto-avaliação sobre a satisfação pessoal auferida com o resultado operacional das atividades empreendidas.

\section{Caracterização Socioeconômica do Desenvolvimento nos Municípios de Cachoeiras de Macacu e Nova Friburgo}

Analisando o Índice de Desenvolvimento Humano dos Municípios (IDHM), que considera as variáveis longevidade, educação e renda, o município com o indicador mais elevado na região serrana foi Nova Friburgo (Tabela I). O IDHM varia de 0 a 1 , considerando que quanto mais próximo de 1 maior é o desenvolvimento humano do 
município. Há 5 faixas de desenvolvimento: muito baixo (igual ou inferior a 0,499); baixo (entre 0,500 e 0,599); médio (entre 0,600 e 0,699); alto (0,700 a 0,799); e muito alto (igual ou superior a 0,800). Cachoeiras de Macacu passou de desenvolvimento baixo, em 2000, para alto, em 2010. (SEBRAE, 2015)

Tabela I - Ranking do IDHM em 2000 e $2010^{5}$

\begin{tabular}{|c|c|c|}
\hline \multirow{2}{*}{ Município } & \multicolumn{2}{|c|}{ Ranking IDHM/RJ } \\
\cline { 2 - 3 } & 2000 & 2010 \\
\hline Cachoeiras de Macacu & $64^{\circ}$ & $58^{\circ}$ \\
\hline Nova Friburgo & $7^{\circ}$ & $11^{\circ}$ \\
\hline
\end{tabular}

O município de Cachoeiras de Macacu possui área territorial de $953,8 \mathrm{Km}^{2}$ e abrigava, em 2000, uma população de 48.543 habitantes com densidade demográfica de $53 \mathrm{hab} / \mathrm{km}^{2}$, destes, 47.015 habitantes viviam em área urbana e 7.355 viviam na zona rural, segundo o censo do IBGE (2010). A economia municipal concentra-se no setor terciário de comércio e serviços (49\%), seguida pela indústria $(43 \%)$ e pela agropecuária $(8 \%)^{6}$. A população estimada mais recentemente foi de 55.967 habitantes, segundo dados do IBGE (2014).

Nova Friburgo é o centro dinâmico da região, possuindo a maior população e a maior densidade demográfica. Apesar de ter perdido posições no IDHM, entre 2000 e 2010, Nova Friburgo possui o $11^{\circ}$ maior IDHM do estado Além disso, seu percentual de pobres é o segundo menor (16,8\%) do ERJ, abaixo apenas de Niterói (14,5\%), e sua renda domiciliar per capita é a $8^{\mathrm{a}}$ maior do estado ( $\mathrm{R} \$$ 878) (SEBRAE, 2015). Possui área territorial de $933.4 \mathrm{Km}^{2}$, e densidade demográfica de $195.07 \mathrm{hab} / \mathrm{Km}^{2}$. A economia municipal concentra-se no setor terciário de comércio e serviços (65\%), seguido pela indústria $(33 \%)$ e pela agropecuária (2\%). A horticultura responde por $81 \%$ da produção agrícola do município, destacando-se também a pecuária bovina e avicultura. Sobressaem no setor secundário as indústrias de confecção de roupas íntimas e têxteis, que juntas representam 39\% da indústria de transformação do município e a metalúrgica que corresponde a $30 \%$ do total $^{7}$. A população estimada saltou de 173.418 habitantes, em 2000, para 182.016 em 2010; destes, 159.355 habitantes viviam na zona urbana e 22.681 viviam na zona rural, segundo o censo do IBGE (2010). A população estimada mais recentemente é de 184.460 habitantes, segundo dados do IBGE (2014).

\footnotetext{
${ }^{5}$ Fonte: IETS, com base nos dados do Atlas do Desenvolvimento Humano no Brasil/PNUD-Ipea-FJP (2013), do PIB dos municípios/IBGE (2011) e do Censo/IBGE (2010).

${ }^{6}$ Informações consultadas no Plano de Manejo do Parque Estadual dos Três Picos.

${ }^{7}$ Idem.
} 


\section{RESULTADOS}

Em relação ao Camping, um levantamento prévio na autarquia municipal de Turismo em Cachoeiras de Macacu, Fundação MacaTur, indicou a existência de apenas um (01) em funcionamento, tendo havido outros dois (02) num passado recente, mas que encerraram suas atividades. Assim como ocorre com algumas Pousadas, em função de o fluxo de visitantes para "banho de rio" se concentrar no verão, a atividade torna-se pouco atrativa para microempreendedores ao longo do ano, levando-os a fechar temporariamente ou definitivamente. Em contraste, entre os três (03) entrevistados em Nova Friburgo, dois (02) estão instalados há mais tempo e vem apresentando uma frequência satisfatória ao longo do ano, principalmente em período de férias, feriados, festas de Ano Novo e Carnaval. Um (01) foi recentemente instalado, não tendo tempo hábil para avaliar se e quando vai haver o retorno sobre o investimento, segundo a responsável entrevistada.

Em relação aos Refúgios, foram contatados um total de seis (06) proprietários na localidade de Três Picos, tendo sido possível agendar e realizar a entrevista com apenas três (03) deles. Os relatos mostraram que a alta temporada corresponde à época mais fria e seca mas, como tem havido longos períodos de estiagem acompanhados de muito calor no verão, tem havido uma frequência satisfatória ao longo do ano com picos no verão e, no inverno devido ao frio. Foi relatado por um entrevistado haver uma mudança na preferência de hóspedes contumazes de alojamentos coletivos por quartos, que oferecem maior privacidade.

Assim, neste diagnóstico preliminar, foram identificados quatro (04) campings e três (03) meios de hospedagem que empregam mão de obra doméstica, com localização e características dos atrativos encontrados de acordo com a Tabela II abaixo.

Tabela II - Localização, tipo de empreendimento, quantidade estimada na localidade, amostra, natureza da ocupação e expediente de Campings e Refúgios nas localidades de Guapiaçu (Cachoeiras de Macacu), Lumiar e Três Picos (Nova Friburgo)

\begin{tabular}{|c|c|c|c|c|c|c|}
\hline \multirow{2}{*}{ Localidade } & Tipo de & Quantidade & \multirow{2}{*}{ Amostra } & \multicolumn{2}{|c|}{ Pessoal ocupado } & \multirow{2}{*}{ Expediente } \\
\cline { 5 - 6 } Empreendimento & Estimada & & doméstico & temporário & Finais de \\
& Camping & 01 & 01 & 2 & 1 & $\begin{array}{c}\text { Finana } \\
\text { semana }\end{array}$ \\
\hline Lumiar & Camping & 03 & 03 & 6 & 3 & $24 \mathrm{~h}$ \\
\hline Três Picos & Refúgios & 06 & 03 & 6 & 6 & $\begin{array}{c}\text { Finais de } \\
\text { semana e 24h }\end{array}$ \\
\hline & Totais & 10 & 07 & 14 & 10 & \\
\hline
\end{tabular}

Em relação à preparação para a atividade e à gestão financeira, apenas os Campings 1 e 3 são formalizados como Microempreendor Individual (MEI) e, apenas o Camping 3 busca registrar em papel e separar a receita proveniente do camping das despesas pessoais, tendo buscado apoio para formalização como MEI através do SEBRAE. 
Quanto ao resultado operacional (lucro) com a atividade, dos quatro (04) campings, dois (02) vem apresentando um desempenho insatisfatório para os proprietários, os Campings 1 e 3. Os Campings 2 e 4 vem apresentando uma frequencia mínima mas regular ao longo do ano, alternando com picos de frequencia. Em relação aos três (03) Refúgios, dois (02) vem apresentando um desempenho insatisfatório, os Refúgios 2 e 3, enquanto o Refúgio 1 vem apresentando uma frequencia mais intensa ao longo do ano, chegando a momentos de pico tanto na alta como na baixa temporada.

Em relação à naturalidade, todos eram nascidos no Estado do Rio de Janeiro, porém entre os sete (07) microempreendedores, apenas dois eram "nativos" da região serrana, um (01) era nascido em Teresópolis, tendo comprado a propriedade no Guapiaçu, e um (01) em Nova Friburgo herdou a propriedade dos pais, que está passando por regularização fundiária por usucapião. Outros cinco (05) microempreendedores são oriundos do município do Rio de Janeiro e, por diferentes motivos, adquiriram propriedades na região entre os anos 1980 e 1990 (Tabela III).

Tabela III - Tipo de microempreendimento: Camping (C), Refúgio (R), Forma de obtenção, Ano de inauguração, Facilidades oferecidas, Lotação máxima e Tarifa por pessoa (pernoite) por localidade (2015).

\begin{tabular}{|c|c|c|c|c|c|c|}
\hline Localidades & Tipo & $\begin{array}{c}\text { Obtenção } \\
\text { /Tamanho } \\
\text { do Imóvel }\end{array}$ & $\begin{array}{c}\text { Ano de } \\
\text { Inaugu- } \\
\text { ração }\end{array}$ & Facilidades & $\begin{array}{c}\text { Lotação } \\
\text { máxima }\end{array}$ & $\begin{array}{c}\text { Tarifa } \\
\text { /pessoa } \\
\text { (R\$) }\end{array}$ \\
\hline Guapiaçu & C 1 & $\begin{array}{c}\text { Compra / } \\
6.800 \mathrm{~m}^{2}\end{array}$ & 2012 & $\begin{array}{c}\text { Cozinha com fogão, } \\
\text { geladeira, utensílios, } \\
\text { churrasqueira }\end{array}$ & 45 & 15 \\
\hline Lumiar & C 2 & $\begin{array}{c}\text { Compra / } \\
28.000 \mathrm{~m}^{2}\end{array}$ & 2011 & $\begin{array}{c}\text { Cozinha com fogão e } \\
\text { geladeira, ducha natural, } \\
\text { redário, churrasqueira, } \\
\text { venda de refeições, } \\
\text { bebidas, acesso à internet }\end{array}$ & 40 & 30 \\
\hline Lumiar & C 3 & $\begin{array}{c}\text { Compra / } \\
30.000 \mathrm{~m}^{2}\end{array}$ & 1996 & $\begin{array}{c}\text { Cozinha com fogão, } \\
\text { geladeira, utensílios, } \\
\text { fogão à lenha e } \\
\text { churrasqueira. }\end{array}$ & 100 & 25 \\
\hline Lumiar & C 4 & $\begin{array}{c}\text { Usucapião / } \\
81.000 \mathrm{~m}^{2}\end{array}$ & 2014 & $\begin{array}{c}\text { Refeições, bebidas, mapa } \\
\text { da região. }\end{array}$ & 100 & 30 \\
\hline Três Picos & R 1 & $\begin{array}{c}\text { Compra / } \\
54.000 \mathrm{~m}^{2}\end{array}$ & 1997 & $\begin{array}{c}\text { Cozinha com fogão, } \\
\text { geladeira, utensílios, } \\
\text { cerveja artesanal, pizza à } \\
\text { lenha }\end{array}$ & 20 & 30 \\
\hline Três Picos & R 2 & $\begin{array}{c}\text { Compra / } \\
68.000 \mathrm{~m}^{2}\end{array}$ & 1989 & $\begin{array}{c}\text { Cozinha com fogão, } \\
\text { geladeira, refeições, } \\
\text { cerveja artesanal, } \\
\text { utensílios }\end{array}$ & 20 & 30 \\
\hline Três Picos & R 3 & $\begin{array}{l}\text { Compra / } \\
27.200 \mathrm{~m}^{2}\end{array}$ & 1992 & $\begin{array}{c}\text { Cozinha com fogão, } \\
\text { geladeira, refeições, } \\
\text { utensílios }\end{array}$ & 15 & 30 \\
\hline
\end{tabular}


Todos os microempreendimentos dispunham de atrativos naturais no interior ou próximo das propriedades onde estão instalados, uns mais ou menos atrativos, outros mais ou menos distantes. No entanto, existem "singularidades"; uma combinação entre atrativo que oferece uma experiência singular, de fácil acesso e com poucas opções de hospedagem de baixo custo mais próximas, atraindo um fluxo maior de turistas ao longo do ano, como uma cachoeira ou vista panorâmica espetacular. Não havendo este atrativo "singular" ou serviços de alimentação, por exemplo, resta investir em opções de consumo e entretenimento dentro da própria propriedade ou construir parcerias para o traslado até os atrativos naturais mais próximos (Tabela IV).

Tabela IV - Tipo de microempreendimento: Camping (C), Refúgio (R), atividades sugeridas num raio de até $1 \mathrm{~km}$, Acesso, transporte público, meios de comunicação, forma de abastecimento de água e separação prévia e existência de coleta seletiva de resíduos por localidade.

\begin{tabular}{|c|c|c|c|c|c|c|}
\hline Localidades & Tipo & $\begin{array}{l}\text { Atividades } \\
(<1 \mathbf{k m})\end{array}$ & Acesso & $\begin{array}{l}\text { Transporte } \\
\text { Público }\end{array}$ & $\begin{array}{c}\text { Abastecimento } \\
\text { de Água }\end{array}$ & $\begin{array}{c}\text { Separação / } \\
\text { Coleta } \\
\text { Seletiva }\end{array}$ \\
\hline Guapiaçu & C 1 & $\begin{array}{l}\text { Banho de rio, } \\
\text { caminhadas }\end{array}$ & $\begin{array}{c}\text { Estrada } \\
\text { pavimentada }\end{array}$ & $\begin{array}{l}\text { Três horários } 2^{\mathrm{a}} \\
\text { à } 6^{\mathrm{a}} \text { e dois aos } \\
\text { finais de semana }\end{array}$ & Rede pública & Sim/Não \\
\hline Lumiar & C 2 & $\begin{array}{c}\text { Banho de } \\
\text { riacho, } \\
\text { caminhadas }\end{array}$ & $\begin{array}{l}\text { Estrada não } \\
\text { pavimentada }\end{array}$ & $\begin{array}{c}\text { Três horários de } \\
2^{\mathrm{a}} \text { à domingo }\end{array}$ & Nascente & Sim/Não \\
\hline Lumiar & C 3 & $\begin{array}{c}\text { Banho de rio e } \\
\text { cachoeira }\end{array}$ & $\begin{array}{c}\text { Estrada } \\
\text { pavimentada }\end{array}$ & Regular & Nascente & Sim/Não \\
\hline Lumiar & $\mathrm{C} 4$ & $\begin{array}{l}\text { Banho de rio, } \\
\text { caminhadas }\end{array}$ & $\begin{array}{c}\text { Estrada } \\
\text { pavimentada }\end{array}$ & $\begin{array}{c}\text { Dois horários } \\
\text { durante a } \\
\text { semana }\end{array}$ & Nascente & Sim/Não \\
\hline Três Picos & R 1 & $\begin{array}{c}\text { Banho de riacho, } \\
\text { caminhadas, } \\
\text { escaladas }\end{array}$ & $\begin{array}{l}\text { Estrada não } \\
\text { pavimentada }\end{array}$ & $\begin{array}{c}\text { Dois horários } \\
\text { durante a } \\
\text { semana }\end{array}$ & Nascente & Sim/Não \\
\hline Três Picos & R 2 & $\begin{array}{c}\text { Banho de riacho, } \\
\text { caminhadas, } \\
\text { escaladas }\end{array}$ & $\begin{array}{l}\text { Estrada não } \\
\text { pavimentada }\end{array}$ & $\begin{array}{c}\text { Dois horários } \\
\text { durante a } \\
\text { semana }\end{array}$ & Nascente & Sim/Não \\
\hline Três Picos & R 3 & $\begin{array}{c}\text { Banho de riacho, } \\
\text { caminhadas, } \\
\text { escaladas }\end{array}$ & $\begin{array}{l}\text { Estrada não } \\
\text { pavimentada }\end{array}$ & $\begin{array}{c}\text { Dois horários } \\
\text { durante a } \\
\text { semana }\end{array}$ & Nascente & Sim/Não \\
\hline
\end{tabular}

Apesar do potencial turístico dos atrativos naturais tanto em Cachoeiras de Macacu como em Nova Friburgo, estes, por si só, não garantem uma maior taxa de ocupação nos meios de hospedagem. Nas falas dos entrevistados constatou-se a carência de uma "casa de cultura" ou uma estrutura que pudesse abrigar exposições, festas, eventos, e mesmo uma praça mais acolhedora no Guapiaçu.

Em Nova Friburgo, os proprietários de Refúgios mostraram-se preocupados com uma possível falta de planejamento territorial que leve à uma ocupação urbana mais intensa ou ao turismo desordenado, descaracterizando a paisagem rural como poderia vir a acontecer a partir da pavimentação das estradas de acesso e construção de pontes de concreto no lugar das de madeira. A conservação de estradas de terra e a melhoria da comunicação (celular, 
internet) seria um ponto em comum entre Lumiar e Três Picos. Neste último foram citados a necessidade de melhor estrutura e ações de Educação Ambiental pelo Parque Estadual dos Três Picos, cursos de capacitação em Turismo, entre outros temas ambientais, criação de RPPN's, abertura de opções de cafeteria e restaurante no Vale João Brandt, no Três Picos, que pudessem expor artesanato, panfletos de divulgação, souvenirs mais próximos dos pontos de concentração de turistas nos Refúgios. Lumiar dispõe de acesso principal pavimentado, concentrando várias opções de hospedagem, bares e restaurantes na zona urbana, mas carece de um centro de informações turísticas e mais presença da Guarda Municipal em função do trânsito. Um ponto fraco em comum nas falas, nas três localidades, foi a insuficiência de transporte público, sendo mais sentido em Três Picos e Lumiar (localidades Pedra Riscada e Santa Luzia) pela inexistência de horários regulares aos finais de semana.

\section{CONCLUSÕES}

Nas entrevistas ficou evidente que a Hospitalidade dos Campings e Refúgios é mais doméstica do que profissional, não no sentido da qualidade do atendimento, mas pela relação dos proprietários com a busca de lucro. Dos sete (07) entrevistados, a atividade constitui uma fonte de renda complementar para cinco (05) entrevistados, o que auxilia as despesas com a manutenção da residência e da propriedade. Dois (02) entrevistados são inscritos como Microempreendedor Individual (MEI), e apenas uma (01) buscou a assessoria do SEBRAE/RJ.

A maior motivação dos microempreendedores é de oferecer o melhor atendimento possível satisfazendo os clientes com os recursos já disponíveis, não ambicionam expandir a capacidade atual. Desfrutam da propriedade conciliando o modo de vida rural no caso do Guapiaçu e Lumiar, ou a prática de escaladas no caso dos Três Picos, com a oferta de alojamento ou área livre para barracas com estruturas de cozinha e banheiro de uso coletivo onde o proprietário (anfitrião) compartilha experiências em contato direto e frequente com os turistas (hóspedes).

Nos Campings não há um perfil bem definido de frequentadores; em geral dispõe de automóveis, são casais, famílias, grupos de jovens e membros de motoclubes. A baixa frequencia leva os microempreendedores a se dividirem entre outras ocupações para conseguirem se manter ao longo do ano. Nenhum dos proprietários dos campings entrevistados sobrevive às custas meramente da renda dos campistas, acabam desenvolvendo outras atividades ligadas à produção rural e construção civil. A exposição à chuva e ao frio são variáveis que conferem maior vulnerabilidade à frequencia de turistas nos Campings, sendo importante que os proprietários promovam investimentos na prevenção ou mitigação para melhor acomodação dos turistas menos preparados e aumento da chance de retorno dos mais experientes.

Uma característica marcante é a presença da responsabilidade compartilhada entre casais tanto em Campings como Refúgios, que se revezam no cuidado com a casa, filhos 
pequenos, cultivos, cães, criações e os turistas, desenvolvendo simultaneamente atividades remuneradas em outros ramos durante a semana. É comum a contratação de prestadores de serviços para instalações, reparos e conservação da área externa, ou diaristas para a limpeza e arrumação gerando despesas que frequentemente não são cobertas pelas receitas de poucos hóspedes.

Em relação aos Refúgios, situados próximo aos limites do Parque Estadual dos Três Picos, a alta temporada corresponde aos meses de maior estiagem, de maio a outubro, apesar de haver aumento da frequencia em períodos de estiagem, em qualquer época. Os frequentadores são predominantemente montanhistas que buscam caminhadas e escaladas, havendo potencial para uma maior segmentação e atração de público com outros perfis que não apenas os caminhantes e escaladores.

Gomes (2008), abordando a tema da participação de agentes locais em regiões turísticas dentro da política de circuitos da Serra do Cipó, Vales e Fazendas e Serra da Canastra, em Minas Gerais, conceituou o circuito como uma estrutura de governança que busca coordenar o desenvolvimento do turismo da região de maneira integrada formando asssim uma rede entre os agentes. Sugere ainda que por haver um ambiente institucional favorável preexistente, a criação de uma entidade gestora do turismo regional facilitou a comunicação entre os agentes locais e a administração pública estadual e federal, e também com outras organizações (SEBRAE, SENAC, SENAR), controlando mais o oportunismo, contribuindo para a redução das incertezas através de uma maior troca de informações, aproximando agentes localizados em municípios díspares, e também para viabilizar projetos que as associações preexistentes tinham maior dificuldade para implementar. Ressalta que todos devem colaborar, não apenas financeiramente, considerando haver uma acomodação natural dos associados a partir da "institucionalização", e que deve haver empenho da diretoria buscando conhecer os motivos da baixa frequencia de associados, reunindo aqueles que realmente têm mais disposição e interesse para ajudar.

Ao longo de décadas, Campings e Refúgios vem acolhendo turistas de várias procedências que trocam o conforto de suas residências, ainda que por pouco tempo, preferindo acomodações simples, mas acolhedoras, para estarem em contato mais próximo com a natureza. Acreditamos que aliar a adoção de estratégias de Circuitos Turísticos às iniciativas de microempreendedores abre mais caminhos para a construção de parcerias para divulgação e planejamento de ações mais eficientes em relação ao dimensionamento da infraestrutura oferecida nestas localidades, podendo resultar no aumento do retorno e da frequencia de novos turistas, assim como despertar mais iniciativas de integração entre propriedades com potencial de incrementar o Ecoturismo através de atividades de Turismo Rural.

A maioria das propriedades rurais abordadas nesta pesquisa possui pequenas dimensões, enquadrando-as como minifúndios, nos quais seria improvável a sustentação econômica a partir de atividades agrícolas desenvolvidas com mão de obra familiar sem a utilização de fertilizantes químicos e produtos agroquímicos para produção em larga escala. 
Trata-se de propriedades que têm potencial para investirem mais em parcerias para o turismo rural e a agricultura orgânica nas suas imediações, ao nível micro, não apenas para consumo próprio mas como um diferencial para os próprios moradores da região, visitantes de um dia e hóspedes, ou mesmo optarem por se converter em Reservas Particulares do Patrimônio Natural (RPPN).

\section{REFERÊNCIAS BIBLIOGRÁFICAS}

BRASIL. Anuário estatístico de turismo-2014, vol.41, ano base 2013. Ministério do Turismo. Disponível em $<$ http ://www.dadosefatos.turismo.gov.br /export /sites/default/dadosefatos/anuario/downloads_anuario/Anuario_Estatistico_de_Turismo__2014_-_Ano_base_2013.pdf > Acesso : 28/04/2015.

BRASIL. Censo 2010. Instituto Brasileiro de Geografia e Estatística, IBGE. Disponível em: < http://www.ibge.gov.br/home/estatistica/populacao/censo2010/tabelas_pdf/total_populacao_ri o_de_janeiro.pdf > Acesso: 18/04/2015.

BRASIL. Governo do Estado do Rio de Janeiro, Secretaria do Ambiente, Instituto Estadual do Ambiente. Plano de Manejo do Parque Estadual dos Três Picos, $1^{\mathrm{a}}$ revisão, Junho/2009.

BRASIL. População Estimada-2014. Instituto Brasileiro de Geografia e Estatística, IBGE, Disponível em: <ftp://ftp.ibge. gov.br/Estimativas_de_Populacao/Estimativas_20 14/ estimativas_2014_TCU.pdf > Acesso : 11/03/2015.

BRASIL. Ministério do Turismo. Segmentação do turismo e o mercado. / Ministério do Turismo, Secretaria Nacional de Políticas de Turismo, Departamento de Estruturação, Articulação e Ordenamento Turístico, Coordenação Geral de Segmentação. - Brasília: Ministério do Turismo, 2010. 172 p.

CAMARGO, L. O. de L. O domínio da hospitalidade. In: Hospitalidade: cenários e oportunidades. Ada de F. M. Dencker/Marielys S.Bueno (orgs.)- São Paulo: Pioneira Thomsom Learning, 2003.

CRUZ, R. de C. A. Hospitalidade turística e fenômeno urbano no Brasil. In: Hospitalidade: reflexões e perspectivas. - São Paulo: Manole, 2002.

D’ONOFRE, D. G. Uma análise da situação do turismo rural nos distritos de Lumiar e São Pedro da Serra em Nova Friburgo (RJ). Monografia de conclusão de curso de bacharelado em Turismo. Universidade do Estado do Rio de Janeiro, Rio de Janeiro, RJ, Brasil, 2010.

D’ONOFRE, D. G. Temáticas emergentes em turismo rural: os tempos e espaços da hospitalidade nos circuitos turísticos de Nova Friburgo, Rio de Janeiro, Brasil: o hibridismo do doméstico e do comercial, do rural e do urbano. IX Congresso Internacional sobre Turismo Rural e Desenvolvimento Sustentável-CITURDES, USP, São Paulo, 2014. Disponível em: <http://143.107.95 .102/prof/kasolha/ citurdes/anais/pdf /eixo7/GT7_8.pdf> Acesso: 04/05/2015

GOMES, B. M. A. Políticas públicas e as transações em regiões turísticas. Bruno Martins Augusto Gomes - São Paulo: All Print editora. 2008.

IGNARRA, R. L. Fundamentos do turismo./Luiz Renato Ignarra. São Paulo : Pioneira, 1999 
PACHECO, A. L. C.; IRVING, M. de A. Turista: o sujeito oculto da sustentabilidade. In: Turismo e sustentabilidade no Rio de Janeiro/orgs. Roberto Bartholo, Mauricio Delamaro e Luciana Badin.- Rio de Janeiro: Garamond, 2005.

SEBRAE. Dados socioeconômicos dos municípios do Estado do Rio de Janeiro agrupados por região, segundo a divisão de atuação do Sebrae/RJ, 2015. Disponível em: <http://www.sebrae.com.br/sites/PortalSebrae/ufs/rj/institucional/Informa\%C3\%A7\%C3\%B5 es-regionais> Acesso: 29/04/2015 